OPEN ACCESS

Edited by:

Dexter Canoy,

University of Oxford, United Kingdom

Reviewed by:

Tao Yang,

University of Toledo, United States

Shigefumi Okamoto,

Kanazawa University, Japan

*Correspondence:

Bo Yu

yubomd@163.com

Specialty section:

This article was submitted to

Cardiovascular Epidemiology and

Prevention,

a section of the journal

Frontiers in Cardiovascular Medicine

Received: 19 January 2021

Accepted: 13 April 2021

Published: 14 May 2021

Citation:

Guo Y, Li X, Wang Z and Yu B (2021) Gut Microbiota Dysbiosis in Human Hypertension: A Systematic Review of

Observational Studies.

Front. Cardiovasc. Med. 8:650227.

doi: 10.3389/fcvm.2021.650227

\section{Gut Microbiota Dysbiosis in Human Hypertension: A Systematic Review of Observational Studies}

\author{
Yang Guo ${ }^{1}$, Xiaosu $\mathrm{Li}^{2}$, Zhijian Wang ${ }^{2}$ and Bo Yu ${ }^{1 *}$ \\ ${ }^{1}$ Department of Dermatology, Skin Research Institute of Peking University Shenzhen Hospital, Peking University Shenzhen \\ Hospital, Shenzhen Peking University-The Hong Kong University of Science and Technology Medical Center, Shenzhen, \\ China, ${ }^{2}$ Department of Cardiology, Peking University Shenzhen Hospital, Shenzhen, China
}

Introduction: Hypertension is one of the major risk factors to human health and human studies on association between gut microbiota and hypertension or blood pressure have received increased attention. In the present study, we aim to evaluate gut microbiota dysbiosis in human hypertension using a method of systematic review.

Methods: PubMed, EMBASE, and Web of Science databases were searched until March 2021 to identify eligible articles. Additional articles were also identified by searching specific authors in this field. Inclusion criteria were observational studies based on stool samples with hypertension group and control group. Newcastle-Ottawa quality assessment scale (NOS) was used to assess the quality of the included studies. PROSPERO registration number: CRD42020212219.

Results: A total of 17 studies enrolling 9,085 participants were included. Fifteen of the enrolled studies showed good quality and two studies showed fair quality based on NOS. We found alpha diversity in hypertension decreased significantly and microbial structure can be separated compared with control groups. Gut microbiota of hypertension showed depletion of short chain fatty acids (SCFAs) producers and over-growth of some Proteobacteria and Bacteroidetes members. Up-regulation of lipopolysaccharide biosynthesis, phosphotransferase system, ABC transporters, etc. and down-regulation of some amino acid metabolism, etc. in hypertension were reported. Fecal SCFAs levels increased and plasma SCFAs levels decreased in hypertension. Stronger microbial interactions in hypertension were seen.

Conclusion: In conclusion, gut microbiota dysbiosis was observed in hypertension, including decreased diversity, altered microbial structure, compositional change of taxa, alterations of microbial function, nutritional and immunological factors, and microbial interactions. Poor absorption and high excretion of SCFAs may play an important role in the pathogenesis of hypertension. These findings may provide insights into etiology study and new microbial-based therapies of hypertension.

Systematic Review Registration: PROSPERO database, identifier CRD42020212219.

Keywords: hypertension, gut microbiota, metabolism, short chain fatty acids, humans 


\section{INTRODUCTION}

Hypertension is a major risk factor of cardiovascular, cerebrovascular, and kidney disorders, leading to heavy disease burden. Globally, $\sim 1.13$ billion cases in 2015 were reported and the increase was seen largely in low-income and middle-income countries (1). Etiology studies have shown that hypertension is a complex and multifactorial disorder influenced by various factors, including genetic factors $(2,3)$ and lifestyle factors (4), such as diet, obesity, physical inactivity, etc. However, based on a large-scale genome-wide association study, blood pressure-associated SNPs can only explain 3.46 and $3.36 \%$ of the variance in systolic blood pressure (SBP) and diastolic blood pressure (DBP), respectively (2), indicating that other potential risk factors remain to be explored. In terms of treatment, despite multiple options, treatment resistant hypertension is identified in about $20 \%$ of hypertensive cases, with few treatment options (5). Therefore, novel therapeutic approaches for the treatment of hypertension are needed.

There are increasing evidences that gut microbiota dysbiosis is associated with many disorders, one of which is hypertension. Gut microbiota is key to human health, including immune system, metabolism and nutrition benefit, and maintaining healthy of gut microbiota is essential to human health (6, 7). Studies suggested that gut microbiota and its metabolites play a critical role in blood pressure regulation. Short-chain fatty acids (SCFAs), important metabolites of gut microbiota, could affect immune system and epithelial functions in the modulation of blood pressure (8). Meta-analyses showed that higher consumption of fiber, which can be fermented by gut bacteria as a source of SCFAs, was associated with decreased blood pressure $(9,10)$. Human studies on association between gut microbiota and hypertension or blood pressure have received increased attention; it is therefore warranted to summarize the available literatures for understanding the role of gut microbiota in hypertension pathogenesis and offering novel insights for preventive and treatment strategies.

In the present study, we systematically reviewed the current available human studies assessing gut microbiota alterations in hypertension and summarized major findings in this field, providing clues for future studies on etiology and targeted therapy in aspect of gut microbiota.

\section{METHODS}

This systematic review was designed and reported according to the recommendations of the Preferred Reporting Items for Systematic Reviews and Meta-Analyses (PRISMA statement) (11). The study was registered with the PROSPERO database (Registration number: CRD42020212219).

\section{Literature Search and Study Selection}

A systematic search was performed based on PubMed, EMBASE, and Web of Science on September 19, 2020 and updated on March 26, 2021. The full search strategies can be found in Supplementary Table 1. Additionally, other data sources were also considered including contact with experts and review of references cited in the included papers.

The eligibility criteria for study inclusion were established according to the PICOS strategy:

1. Participants/population: people with and without hypertension and with gut microbiota measured (fecal samples);

2. Interventions/exposures: hypertension or blood pressure;

3. Comparators/controls: hypertension group vs. control group;

4. Outcomes: (1) primary outcome: changes of microbiota diversity and differential microbes between hypertension and controls; (2) secondary outcome: major findings of microbiota functions, nutritional and immunological factors, and microbial interactions;

5. Study design: observational studies with hypertension group and control group.

Additionally, the search strategy did not include language restriction; the articles which were not published in English or Chinese and did not provide English or Chinese abstracts were excluded. Conference abstracts were excluded as limited information was reported. Two researchers (Y. G. and X. L.) independently did the literature search and study selection. Discrepancies were resolved through group discussions.

\section{Data Extraction}

Using pre-designed standardized data abstraction forms, two researchers (Y. G. and X. L.) independently extracted characteristics of include studies, with any disagreements resolved by consensus. The extracted information included: authors, publication year, journal, region, study design, method of characterization of the microbiota, major findings, etc.

\section{Assessment of Risk of Bias in Included Studies}

Newcastle-Ottawa quality assessment scale (NOS) (12) was used to assess the quality of the included studies. A star system has been developed in which a study is judged on three broad perspectives: (1) Selection, (2) Comparability, and (3) Exposure/ Outcome. A study can be awarded a maximum of one star for each numbered item within the Selection and Exposure categories; a maximum of two stars can be given for Comparability. Totally, a maximum of nine stars can be given for a study and more stars represent higher quality. Studies were categorized as good quality if the score was $\geq 7$, fair quality if the score was $4 \sim 6$, and poor quality if the score was $<4$ (13).

\section{Outcome Assessment}

The pre-specified primary outcomes were changes of microbiota diversity and differential microbes between hypertension and controls. Alpha diversity is a quantitative measure of community diversity and beta diversity is a measure of similarity between samples (14). Alterations of diversity are associated with perturbations or imbalance in the community composition (generally referred to as dysbiosis). Detection of differential microbes between groups is an exploration of key taxa, which 


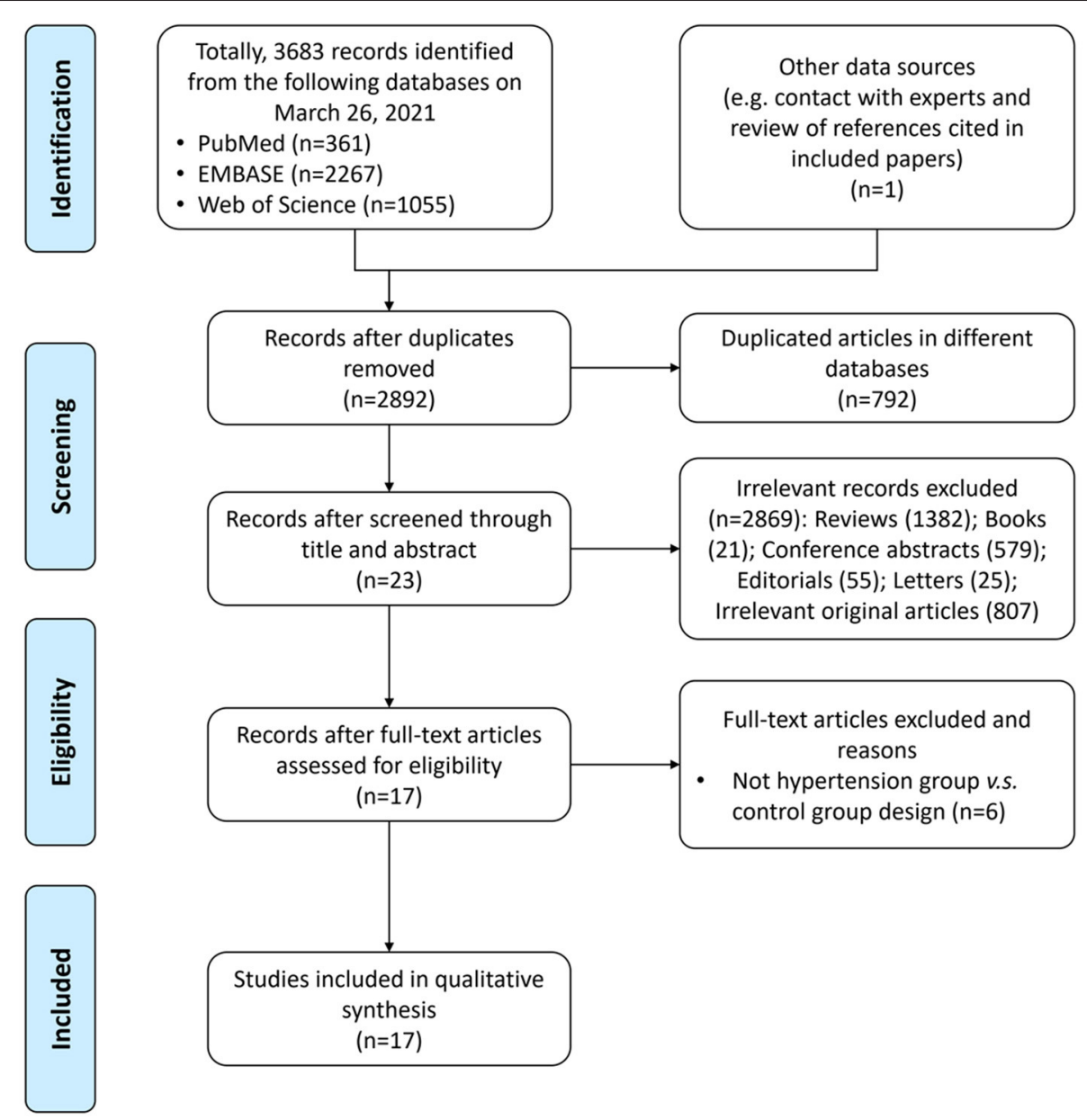

FIGURE 1 | PRISMA flow diagram for study selection.

could be potential biomarkers, and this may offer clues for downstream interventional trials (15).

The secondary outcomes were major findings of microbiota functions, nutritional and immunological factors, and microbial interactions. Findings of microbiota functions predicted using Phylogenetic Investigation of Communities by Reconstruction of Unobserved States (PICRUSt) were summarized and may provide clues for further validation study (16). The nutritional and immunological findings, which are intimately related to the gut microbial profile, include SCFAs, cytokines, inflammatory compounds/anti- inflammatory compounds, immune cells, etc. (7). Furthermore, the microbial interaction analysis may illustrate how microbes interact with each other and the dynamic changes in the pathogenesis of hypertension (17).

\section{RESULTS}

\section{Characteristics of Included Studies}

A total of 3,683 records were identified from the three databases, including PubMed, EMBASE, and Web of Science, and one record was identified by searching publications of specific experts; 792 of them were repeatedly included from more than one search database and were excluded. Totally, 17 articles (1834) with 9,085 participants were included in the final analysis. The study selection process is shown in the PRISMA flow diagram (Figure 1).

The characteristics of included studies were summarized in Table 1. Most of them were published in year 2019 (6/17 studies) (23-28) and year 2020 (6/17 studies) (29-34); in terms of geographical region, most of these researches were conducted in China (9/17 studies) $(18-21,23,25,27,28,30)$ and the US (3/15 studies) $(22,27,31)$, which are two countries with heavy disease burden of hypertension. For study design, most studies enrolled a group of fecal samples from hypertension cases and a group of fecal samples from healthy controls with normal blood pressure; the major exploration was based on comparison between the two groups; three studies $(18,20,24)$ also enrolled subjects of pre-hypertension or in borderline status. Additionally, one study (30) focused on preeclampsia and another one (31) focused on pulmonary arterial hypertension (PAH). As for evaluation method of microbiota, most studies $(23-27,29,30,33,34)(9 / 17$ studies) used $16 \mathrm{~S}$ ribosomal RNA gene sequencing and seven 
TABLE 1 | Characteristics of the included studies.

\begin{tabular}{|c|c|c|c|c|c|}
\hline Study & Country & Cases & Controls & $\begin{array}{l}\text { Total } \\
\text { sample } \\
\text { size }\end{array}$ & $\begin{array}{l}\text { Evaluation of } \\
\text { microbiota }\end{array}$ \\
\hline
\end{tabular}

\section{Hypertension}

Silveira-Nunes et al (33)

Brazil

Reported and treated hypertension (SBP >140 $\mathrm{mmHg}$ and DBP > 90 $\mathrm{mmHg})$ for more than 10 years $(n=$ 48 , mean age: $65.3 \pm 15.5 \mathrm{y}$, male/female: 14:34)

Palmu et al. (32) Finland

Calderon-Perez

et al. (29)

Takagi et al. (34)

Japan

Sun et al. (27)

Mushtaq et al. (26)

China

Dan et al. (23)

China

$\mathrm{SBP} \geq 140 \mathrm{mmHg}$ or $\mathrm{DBP} \geq 90$ mmHg ( $n=62$, mean age: 69.322 \pm 10.613 y, male/female: 0:62)

Li et al. (25)

China
Those with no report of

hypertension ( $n=32$

mean age: $63.3 \pm 15.0 \mathrm{y}$,

male/female: $7: 25)$

Normotensive individuals from the same cohort $(n=$ 3,662, mean age for all subjects: $49.2 \pm 12.88 \mathrm{y}$ male/female for all subjects: 3,819:3,134)

SBP $<120 \mathrm{mmHg}(n=32$, mean age: $41.1 \pm 9.1 \mathrm{y}$, male/female: 16:16)

Healthy controls without gastrointestinal inflammatory diseases or functional gastrointestinal disorders, without use of antibiotics, corticosteroids, immunosuppressants, or acid-suppressing agents within the past 3 months, and without as a history of underlying malignant disease $(n=54$, median age: 65.5 (16-88) y, male/female: 21:33)

Healthy controls ( $n=343$, mean age for all subjects: $55.3 \pm 3.4$ y, male/female for all subjects: 244:285)

Healthy controls with no history of hypertension, or any other cardiovascular or chronic metabolic disease ( $n=30$, mean age: $60.5 \pm$

11 y, male/female: 16/14)

$90 \mathrm{mmHg} \leq \mathrm{SBP} \leq 140$ $\mathrm{mmHg}$ and $60 \mathrm{mmHg} \leq$ $\mathrm{DBP} \leq 90 \mathrm{mmHg}(n=67$, mean age: $69.492 \pm 9.630$ y, male/female: 0:67)

Healthy controls $(n=42$, mean age: $59.3 \pm 9.2$ y, male/female: 17:25)
80

16S rRNA gene sequencing

6,953

Metagenomic sequencing

16S rRNA gene sequencing

151

16S rRNA gene sequencing

16S rRNA gene sequencing

16S rRNA gene sequencing and quantitative PCR

16S rRNA gene sequencing sequencing $\mathrm{mmHg}$, or by self-reported use of antihypertensive medications in the last 2 weeks irrespective of BP values

Naive hypertension $(n=63$, mean age: $58.4 \pm 10.2$ y, male/female: 35/28)

Anti-hypertensive ( $n=104$, mean age: $59.8 \pm 9.3$ y, male/female: 50:54) 
TABLE 1 | Continued

\begin{tabular}{|c|c|c|c|c|c|}
\hline Study & Country & Cases & Controls & $\begin{array}{l}\text { Total } \\
\text { sample } \\
\text { size }\end{array}$ & $\begin{array}{l}\text { Evaluation of } \\
\text { microbiota }\end{array}$ \\
\hline Jin et al. (21) & China & $\begin{array}{l}\mathrm{SBP} \geq 140 \mathrm{mmHg} \text { or } \mathrm{DBP} \geq 90 \\
\mathrm{mmHg}(n=73, \text { mean age: } 53.7 \pm \\
5.7 \mathrm{y}, \text { male/female: } 66: 7)\end{array}$ & $\begin{array}{l}\mathrm{SBP}<120 \mathrm{mmHg} \text { and } \\
\mathrm{DBP}<80 \mathrm{mmHg}(n=68 \\
\text { mean age: } 52.5 \pm 5.7 \mathrm{y} \\
\text { male/female: } 59: 9)\end{array}$ & 141 & $\begin{array}{l}\text { Metagenomic } \\
\text { sequencing }\end{array}$ \\
\hline \multicolumn{6}{|c|}{ Hypertension and borderline hypertension/Pre-hypertension } \\
\hline Huart et al. (24) & Belgium & $\begin{array}{l}\text { Hypertension: mean } 24-\mathrm{h} \text { SBP } \\
\text { levels } \geq 130 \mathrm{~mm} \mathrm{Hg} \text { or DBP } \\
\geq 80 \mathrm{~mm} \mathrm{Hg} \text { or in case of use of } \\
\text { antihypertensive medications } \\
\text { whatever the BP levels ( } n=38, \\
\text { mean age: } 52.5 \pm 8.2 \mathrm{y}, \\
\text { male/female: } 38: 0) \\
\text { Borderline hypertension: mean } \\
\text { 24-h BP levels }<130 / 80 \mathrm{~mm} \mathrm{Hg} \\
\text { with either isolated daytime } \\
\text { hypertension (SBP } \geq 135 \mathrm{~mm} \mathrm{Hg} \\
\text { and DBP } \geq 85 \mathrm{~mm} \mathrm{Hg} \text { ) or nocturnal } \\
\text { hypertension }(\mathrm{SBP} \geq 120 \mathrm{~mm} \mathrm{Hg} \text { or } \\
\text { DBP } \geq 70 \mathrm{~mm} \mathrm{Hg})(n=7, \text { mean } \\
\text { age: } 50.3 \pm 13.3 \mathrm{y}, \\
\text { male/female: } 7: 0)\end{array}$ & $\begin{array}{l}\text { Untreated individuals with } \\
\text { mean } 24-\mathrm{h} \mathrm{BP} \text { levels } \\
<130 / 80 \mathrm{~mm} \mathrm{Hg}(n=9 \text {, } \\
\text { mean age: } 46.2 \pm 11.4 \mathrm{y} \\
\text { male/female: } 9: 0)\end{array}$ & 54 & $\begin{array}{l}\text { 16S rRNA gene } \\
\text { sequencing }\end{array}$ \\
\hline Han et al. (20) & China & $\begin{array}{l}\text { Hypertension patients: SBP } \\
\geq 140 \mathrm{mmHg} \text {, or DBP } \geq 90 \mathrm{mmHg} \\
\text { without antihypertensive treatments } \\
\text { ( } n=99 \text {, not report characteristics } \\
\text { of final included subjects) } \\
\text { Pre-hypertension persons: } 125 \\
\mathrm{mmHg}<\mathrm{SBP} \leq 139 \mathrm{mmHg} \text { or } 80 \\
\mathrm{mmHg}<\mathrm{DBP} \leq 89 \mathrm{mmHg} \text { without } \\
\text { antihypertensive treatments ( } n= \\
56, \text { not report characteristics of final } \\
\text { included subjects) }\end{array}$ & $\begin{array}{l}\mathrm{SBP} \leq 125 \mathrm{mmHg} \text { and } \\
\text { DBP } \leq 80 \mathrm{mmHg} \text { without } \\
\text { antihypertensive } \\
\text { treatments ( } n=44 \text {, not } \\
\text { report characteristics of } \\
\text { final included subjects) }\end{array}$ & 199 & Viral sequencing \\
\hline Li et al. (18) & China & $\begin{array}{l}\text { Hypertension patients: } 140 \\
\mathrm{mmHg} \leq \mathrm{SBP}, \text { or } 90 \mathrm{mmHg} \leq \mathrm{DBP} \\
(n=99, \text { mean age: } 53.6 \pm 5.5 \mathrm{y}, \\
\text { male/female: } 93: 6) \\
\text { Pre-hypertension persons: } 125 \\
\mathrm{mmHg}<\mathrm{SBP} \leq 139 \mathrm{mmHg} \text {, or } 80 \\
\mathrm{mmHg}<\mathrm{DBP} \leq 89 \mathrm{mmHg}(n= \\
56, \text { mean age: } 51.8 \pm 6.6 \mathrm{y}, \\
\text { male/female: } 52: 4)\end{array}$ & $\begin{array}{l}\mathrm{SBP} \leq 125 \mathrm{mmHg} \text {, or DBP } \\
\leq 80 \mathrm{mmHg}(n=41, \text { mean } \\
\text { age: } 53.7 \pm 5.9 \mathrm{y} \\
\text { male/female: } 32: 9)\end{array}$ & 196 & $\begin{array}{l}\text { Metagenomic } \\
\text { sequencing }\end{array}$ \\
\hline
\end{tabular}




\section{TABLE 1 | Continued}

\begin{tabular}{|c|c|c|c|c|c|}
\hline Study & Country & Cases & Controls & $\begin{array}{l}\text { Total } \\
\text { sample } \\
\text { size }\end{array}$ & $\begin{array}{l}\text { Evaluation of } \\
\text { microbiota }\end{array}$ \\
\hline \multicolumn{6}{|l|}{ Preeclampsia } \\
\hline Chang et al. (30) & China & $\begin{array}{l}\text { An elevated systolic BP of } \\
\geq 160 \mathrm{~mm} \mathrm{Hg} \text { or a diastolic BP of } \\
\geq 110 \mathrm{~mm} \mathrm{Hg} \text {, proteinuria of } \geq 3 \\
\mathrm{~g} / 24 \mathrm{~h}(\mathrm{n}=27, \text { mean age: } 31.7 \pm \\
4.9 \mathrm{y}, \text { male/female: } 0: 27)\end{array}$ & $\begin{array}{l}\text { Healthy pregnant control ( } n \\
=36 \text {, mean age: } 30.4 \pm \\
4.1 \mathrm{y} \text {, male/female: } 0: 36)\end{array}$ & 63 & $\begin{array}{l}\text { 16S rRNA gene } \\
\text { sequencing }\end{array}$ \\
\hline \multicolumn{6}{|c|}{ Pulmonary arterial hypertension } \\
\hline Kim et al. (31) & US & $\begin{array}{l}\text { Type } 1 \text { PAH patients (mean } \\
\text { pulmonary arterial pressure } 57.4 \pm \\
16.7 \mathrm{mmHg} \text { ( } n=19 \text {, mean age: } \\
39.5 \pm 12.7 \mathrm{y} \text {, male/female: } 3 / 16 \text {; } \\
\text { final include: } n=18 \text { ) }\end{array}$ & $\begin{array}{l}\text { Age- and sex-matched } \\
\text { healthy controls }(n=16 \text {, } \\
\text { mean age: } 37 \pm 11 \mathrm{y} \\
\text { male/female: } 3 / 13 \text {; final } \\
\text { included: } n=13)\end{array}$ & 31 & $\begin{array}{l}\text { Metagenomic } \\
\text { sequencing }\end{array}$ \\
\hline
\end{tabular}

DBP, diastolic blood pressure; NOS, Newcastle-Ottawa quality assessment scale; PAH, pulmonary arterial hypertension; SBP, systolic blood pressure.

studies $(18,19,21,22,28,31,32)$ used metagenomic sequencing. Moreover, one study (20) utilized viral sequencing to profile the gut virome.

\section{Risk of Bias in Included Studies}

We evaluated the risk of bias for the 17 studies using NOS (Figure 2). The mean NOS score of included studies in the present systematic review was $7.2 \pm 0.7 ; 15$ out of 17 studies showed good quality. However, potential selection bias was observed due to the lack of representativeness of the cases in 15 of 17 studies (Figure 2).

\section{Change of Gut Microbiota Diversity in Hypertension}

Thirteen articles reported the change of alpha diversity in hypertension (Table 2). Some studies showed alpha diversity indexes were decreased in fecal samples of hypertension (18, 19, 28, 33), pre-hypertension (18), preeclampsia (30), and $\mathrm{PAH}$ (31). Another detailed multivariable-adjusted regression analysis of the association between alpha diversity indexes and blood pressure indicated that blood pressure was inversely associated with measures of alpha-diversity (27). For Shannon index, in multivariable-adjusted models between gut microbial alpha diversity and hypertension, odds ratios (ORs) were ranging from 0.82 to 0.90 in different models; for Richness index, ORs were ranging from 0.70 to 0.79 in different models (27). However, some studies suggested that no significant differences in alpha diversity indexes were seen between hypertension and controls $(23,29)$, including the virome study (20); similarly, another multivariable-adjusted regression analysis (32) reported that alpha diversity was not related to any BP variable. Additionally, one study (26) reported that Chao 1 index and abundance-based coverage estimator (ACE) index were higher in hypertension group than controls group. Notably, different indexes representing alpha diversity may show different change trends in one single study $(26,28,33)$. For instance, in one study (33), Shannon index was decreased in hypertension group; but no significant differences were observed in phylogenetic diversity index and OTUs count between hypertension group and control group.

As for beta diversity (microbial community structure), 13 studies reported related findings (Table 2). Most studies (11/13 studies) showed that significant differences between hypertension group and control group were detected (18-20, 22, 23, 26, 27, 30$33)$. Two studies reported that no significant differences were seen $(29,34)$.

\section{Key Taxa Associated With Hypertension}

The major taxa with disparate representation in hypertension were summarized in Table 3. Overall, these studies reported heterogeneous results; therefore, we focus on key taxa which were reported with consistent change across at least two different studies. First, gut microbiota of hypertension showed over-growth of Megasphaera (23, 25, 26), Prevotella (18, 26), Klebsiella (18, 19), Parabacteroides (21, 23), Alistipes (23, 25), Enterobacter (30, 32), Escherichia (26, 30), Shigella (26, 30), etc. Whereas, Faecalibacterium (18, 26, 28, 33), Roseburia (18, 19, 28, 33), Ruminococcus (23, 27), Coprococcus (18, 31), Butyrivibrio (18, 28, 31), Bifidobacterium (18, 30), Sporobacter (23, 27), Akkermansia (27, 28, 31), Bacteroides (26, 31), Eubacterium rectale (22, 30), Faecalibacterium prausnitzii (19, 29), Clostridium (23, 28), Marvinbryantia (23, 28), Subdoligranulum (28, 30), Anaerotruncus (23, 28), Intestinimonas $(23,28)$, etc. were depleted in hypertension. In short, SCFA producers, including Faecalibacterium, Roseburia, Ruminococcus, Bifidobacterium, Akkermansia, and Bacteroides, etc. were depleted in hypertension; on the contrary, some Proteobacteria and Bacteroidetes members were enriched in hypertension, such as Klebsiella, Prevotella, and Enterobacter.

Regarding the two studies, which were focusing on PAH (31) and preeclampsia (30), we summarized specific bacteria reported concerning $\mathrm{PAH}$ and preeclampsia in genus and species levels (Table 3 ). We found that Collinsella aerofaciens (species) enriched and Eubacterium (genus) depleted specifically in PAH; for preeclampsia, it was shown that Blautia (genus) and Eubacterium hallii (species) depleted specifically in preeclampsia. 


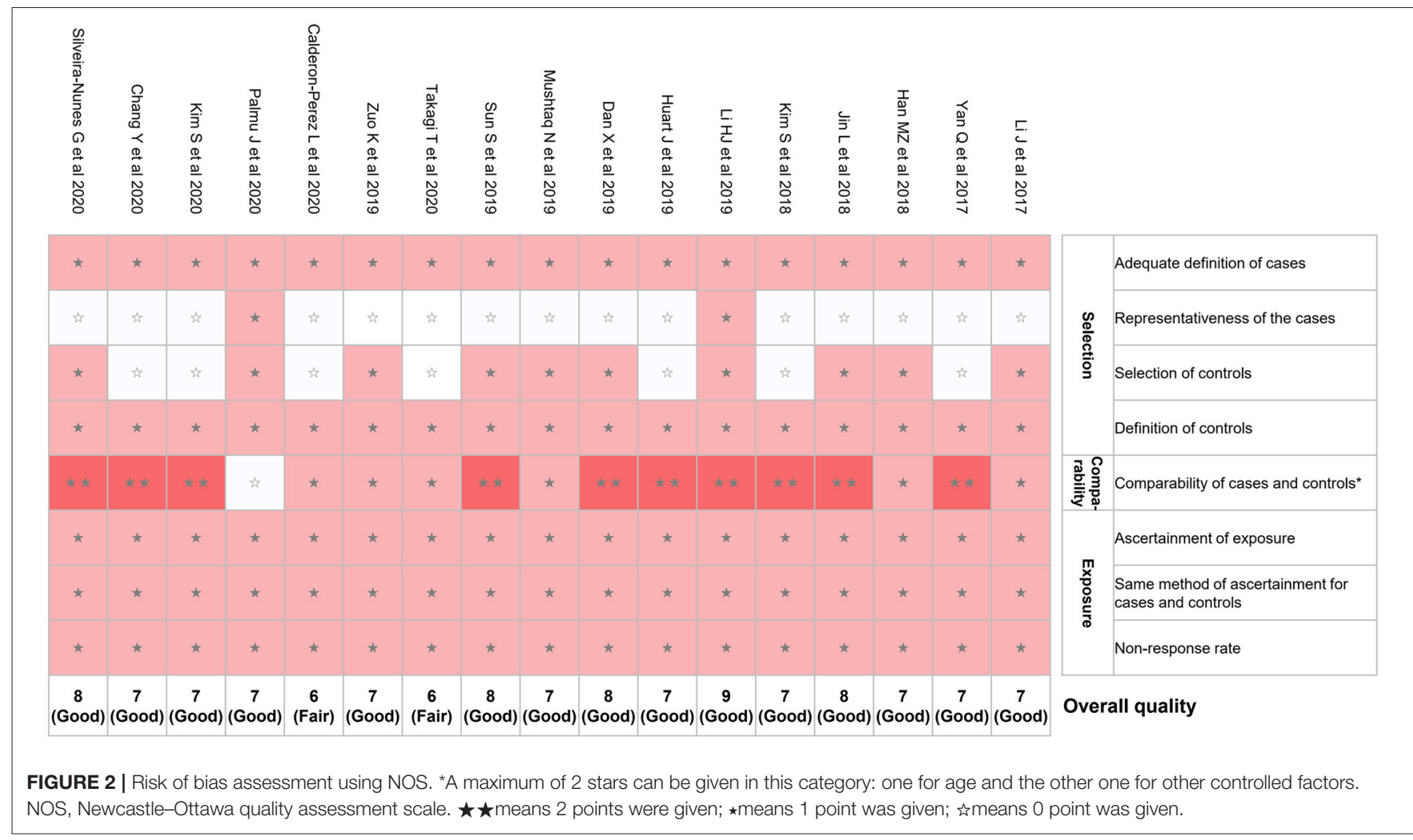

\section{Alterations of Gut Microbial Function in Hypertension}

Nine studies performed function analyses of gut microbiota using PICRUSt (Table 4). Similarly, these studies yielded different results for microbial function modification in hypertension and we summarized the common ones. Up-regulation of lipopolysaccharide (LPS) biosynthesis (18, 19, 22, 30), phosphotransferase system (PTS) $(18,22), \mathrm{ABC}$ transporters $(21,22)$, and down-regulation of some amino acid metabolism $(18,19)$ in hypertension were reported.

\section{Alterations of Nutritional and Immunological Factors in Hypertension}

Five studies $(22,24,28-30)$ reported fecal metabolites alterations in hypertension (Table 4). Most studies focused on SCFAs, including acetate, butyrate, and propionate, etc., and related findings were summarized accordingly. Hypertension showed increased fecal SCFAs levels $(24,29)$ and decreased plasma SCFAs levels $(22,29)$. However, as opposed to these results, a preeclampsia study suggested that fecal levels of butyric and valeric acids were lower in preeclampsia (30). One metabolomics research reported multiple metabolites were altered in hypertension, such as lipids, acids, vitamins, etc. (28). Additionally, three studies reported immunological factors alteration in hypertension: pro-inflammatory cytokines, including TNF, IL-6, etc., and compounds, e.g., LPS, were increased (22, 33); anti-inflammatory compounds, such as 3,4,5-trimethoxycinnamic acid, were decreased in hypertension (18).

\section{Alterations of Gut Microbial Interactions in Hypertension}

Two studies $(19,20)$ did microbial interaction analysis of gut microbiota (Table 4). The virome study reported co-occurrence networks linking viruses and bacteria and found increasingly pervasive virus-bacteria linkages from healthy individuals to prehypertension individuals and to hypertension patients (20). In another research, the number of hypertension-associated species showed stronger correlation to the severity of disease (19).

\section{DISCUSSION}

In the present study, we systematically reviewed human studies evaluating alterations of gut microbiota in hypertension and summarized major findings of gut microbiota dysbiosis including diversity, major taxa with disparate representation, microbial function, nutritional and immunological factors, and interactions.

Reduced microbial diversity is commonly recognized as a marker of microbial dysbiosis and many diseases show a dysbiosis characterized by a lower diversity (7). Our study found decreased diversity of gut microbiota in hypertension $(18,19,33)$, pre-hypertension (18), preeclampsia (30), and PAH (31), although a contrary conclusion was also seen (26). In line with human study results, reduced microbial diversity also 
TABLE 2 | Major findings of the included studies on diversity.

\begin{tabular}{|c|c|c|}
\hline Study & Change of alpha diversity in hypertension & Change of beta diversity in hypertension \\
\hline \multicolumn{3}{|l|}{ Hypertension } \\
\hline $\begin{array}{l}\text { Silveira-Nunes et al. } \\
\text { (33) }\end{array}$ & $\begin{array}{l}\text { Shannon index was decreased in hypertension group; } \\
\text { phylogenetic diversity and OTUs count were similar in } \\
\text { hypertension group and control group }\end{array}$ & $\begin{array}{l}\text { Significant differences between hypertension group and } \\
\text { control group were detected }\end{array}$ \\
\hline Palmu et al. (32) & $\begin{array}{l}\text { Alpha diversity was not related to any BP variable in the } \\
\text { multivariable-adjusted models }\end{array}$ & $\begin{array}{l}\text { In multivariable-adjusted models, beta diversity was only } \\
\text { associated with DBP }\end{array}$ \\
\hline $\begin{array}{l}\text { Calderon-Perez et al. } \\
\text { (29) }\end{array}$ & $\begin{array}{l}\text { No significant differences of Shannon index and Chao } 1 \\
\text { were seen between different groups }\end{array}$ & No significant differences were detected \\
\hline Takagi et al. (34) & $\begin{array}{l}\text { No significant differences of Shannon index and the } \\
\text { observed species were seen between different groups }\end{array}$ & No significant differences were detected \\
\hline Sun et al. (27) & $\begin{array}{l}\text { Hypertension and SBP were inversely associated with } \\
\text { measures of alpha-diversity, including Richness (ORs: } \\
0.70 \sim 0.79 \text { in different models) and the Shannon Diversity } \\
\text { Index (ORs: 0.82 0.90 in different models) }\end{array}$ & $\begin{array}{l}\text { Beta diversity was significantly associated with both } \\
\text { hypertension and SBP in all multivariable-adjusted models }\end{array}$ \\
\hline Mushtaq et al. (26) & $\begin{array}{l}\text { Observed species, OTUs, Shannon, Simpson, and Good's } \\
\text { coverage were similar in hypertension group and control } \\
\text { group; chao1 and ACE were higher in hypertension group } \\
\text { than controls group }\end{array}$ & $\begin{array}{l}\text { Significant differences between hypertension group and } \\
\text { control group were detected }\end{array}$ \\
\hline Dan et al. (23) & $\begin{array}{l}\text { No significant differences were seen between hypertension } \\
\text { group and control group }\end{array}$ & $\begin{array}{l}\text { Significant differences between hypertension group and } \\
\text { control group were detected }\end{array}$ \\
\hline Zuo et al. (28) & $\begin{array}{l}\text { Shannon index and Pielou evenness were decreased in } \\
\text { hypertension group; Chao richness was similar in } \\
\text { hypertension group and control group }\end{array}$ & - \\
\hline Kim et al. (22) & - & $\begin{array}{l}\text { Samples were separate significantly based on bacterial } \\
\text { taxonomy }\end{array}$ \\
\hline Yan et al. (19) & Shannon index was decreased in hypertension group & $\begin{array}{l}\text { Overlaps were seen only in part with taxonomic composition } \\
\text { based on Bray-Curtis distances }\end{array}$ \\
\hline \multicolumn{3}{|c|}{ Hypertension and borderline hypertension/Pre-hypertension } \\
\hline Han et al. (20) & $\begin{array}{l}\text { No significant differences were seen between different } \\
\text { groups }\end{array}$ & Samples were stratified into two viral-types \\
\hline Li et al. (18) & $\begin{array}{l}\text { Shannon index was decreased in hypertension group and } \\
\text { pre-hypertension group }\end{array}$ & $\begin{array}{l}\text { Samples were clustered into two enterotypes by PCA of } \\
\text { Jensen-Shannon divergence }\end{array}$ \\
\hline \multicolumn{3}{|l|}{ Preeclampsia } \\
\hline Chang et al. (30) & $\begin{array}{l}\text { Shannon index and Sobs index were decreased in } \\
\text { hypertension group }\end{array}$ & $\begin{array}{l}\text { Significant differences between hypertension group and } \\
\text { control group were detected }\end{array}$ \\
\hline \multicolumn{3}{|c|}{ Pulmonary arterial hypertension } \\
\hline Kim et al. (31) & $\begin{array}{l}\text { Shannon index, Simpson's index and Evenness were } \\
\text { decreased in PAH group }\end{array}$ & $\begin{array}{l}\text { Significant differential taxonomic profiles between PAH and } \\
\text { control group were observed }\end{array}$ \\
\hline
\end{tabular}

BP, blood pressure; DBP, diastolic blood pressure; OR, odds ratio; OTUs, operational taxonomic units; PAH, pulmonary arterial hypertension; SBP, systolic blood pressure.

occurs in animal models of hypertension, such as spontaneously hypertensive rat (SHR) (35) and hypertensive obstructive sleep apnea (OSA) rats (36). Additionally, microbial community structure was altered in hypertension as reported in 11 enrolled studies. These findings have emphasized the gut dysbiosis phenomena in hypertension.

Another important assessment for microbiota dysbiosis was to explore differential taxa by comparing hypertension group and healthy control group. According to the available studies, SCFAs producers were depleted and some Proteobacteria and Bacteroidetes members were enriched in hypertension. Similarly, decrease of bacteria that produced SCFAs was seen in SHR (35) and hypertensive OSA rats (36). Furthermore, animal studies showed that acetate (37) and propionate $(38,39)$, two common SCFAs, were associated with reduced blood pressure and showed cardiovascular protective effects. These findings indicated that SCFAsproducing bacteria may be involved in the pathogenesis of hypertension.

Nutritional and immunological factors, which may reflect host-microbiota crosstalk, were summarized and we found that fecal SCFAs levels were increased $(24,29)$ and plasma SCFAs levels were decreased $(22,29)$ in hypertension. SCFAs, including acetate, propionate, and butyrate, are produced by bacterial fermentation of unabsorbed carbohydrates in the colon $(7,40)$. Then SCFAs are secreted into the gut lumen, transported across the epithelial barrier, and transported to the bloodstream (41). As mentioned above in the present study, depletion of SCFAs producing bacteria and increased fecal SCFAs levels in hypertension indicated less SCFAs production 
TABLE 3 | Major taxa with disparate representation in hypertension.

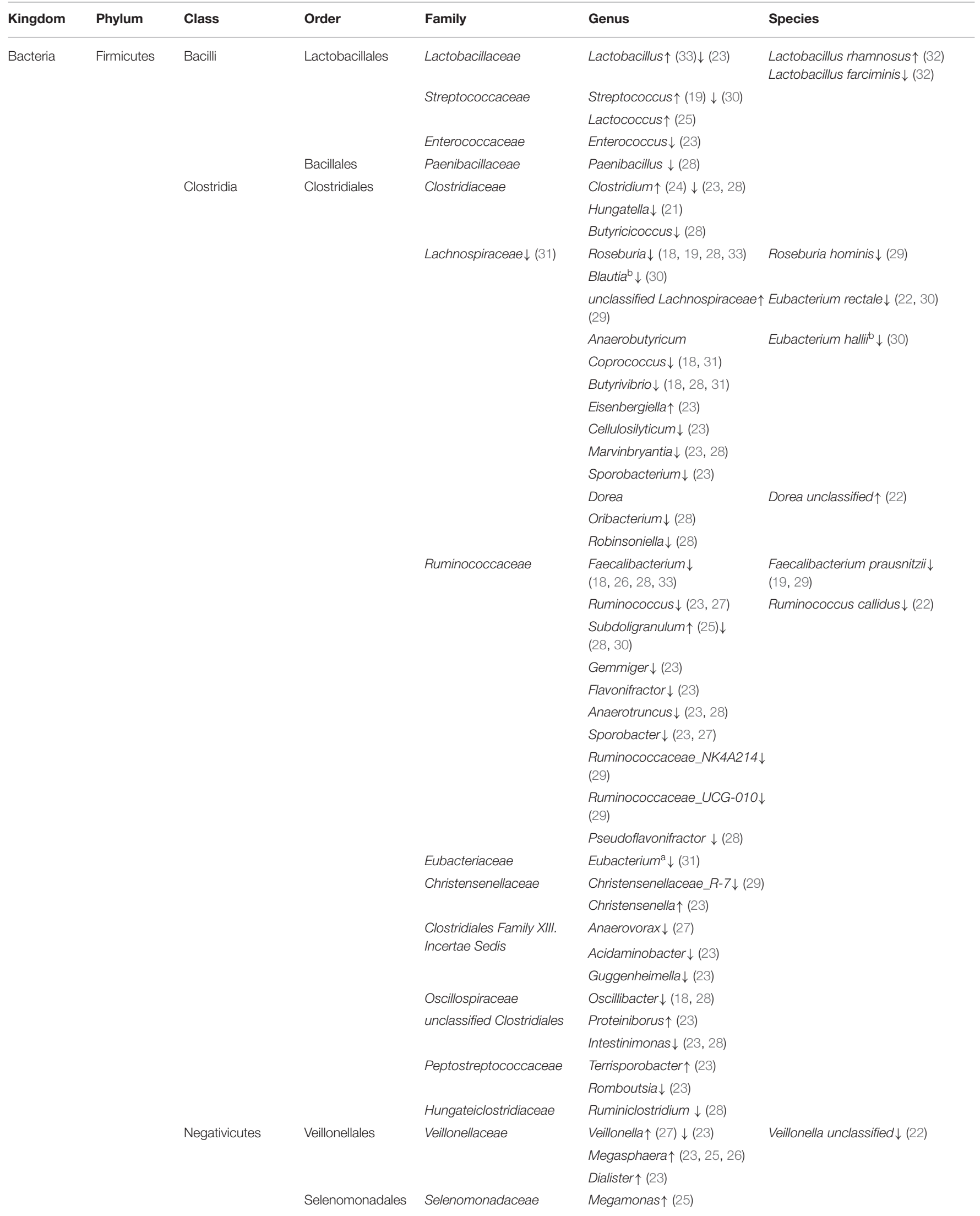


TABLE 3 | Continued

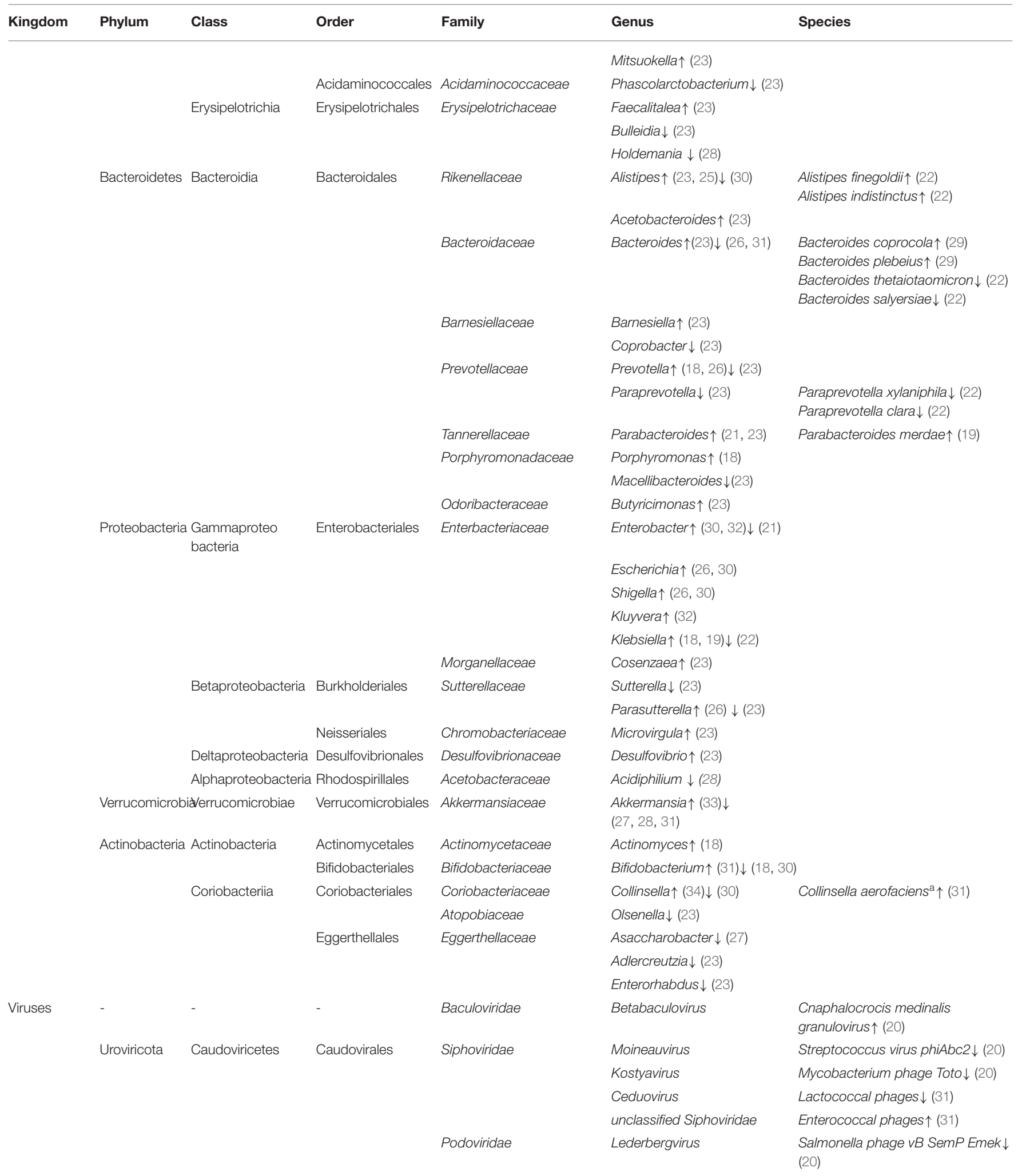

${ }^{a}$ Altered specifically in PAH; ${ }^{b}$ Altered specifically in preeclampsia. 
TABLE 4 | Major findings of microbiota functions, nutritional and immunological factors, and microbial interactions.

$\begin{array}{ll}\text { Study Gut microbial functional alterations } & \text { Nutritional and immunological factors alterations } \\ & \text { interactions } \\ \text { alterations }\end{array}$

\section{Hypertension}

Silveira-Nunes

et al. (33)

Palmu et al. (32)

Calderon-Perez

et al. (29)

Takagi et al. (34)

Up-regulated in hypertension: Metabolic enzyme familie

Zuo et al. (28)

Kim et al. (22)

Jin et al. (21)

Yan et al. (19) and environmental information processing membrane transport

Down-regulated in hypertension: Genetic information processing transcription, glycan biosynthesis and metabolism, and lipid metabolism

Most prominent pathways were related to lipid metabolism, gluconeogenesis, and xenobiotic metabolism, etc.

Up-regulated in hypertension: Electron transport energy transformation, DNA replication, recombination and repair Down-regulated in hypertension: Signal Transduction_Two Component Systems metabolism, anaerobic energy metabolism, DNA

Up-regulated in hypertension: LPS biosynthesis, steroid system

Down-regulated in hypertension: ubiquinone and other terpenoid-quinone biosynthesis, beta-alanine metabolism, selenocompound metabolism, cyanoamino acid metabolism, d-alanine metabolism, one carbon pool by folate, riboflavin metabolism, and folate biosynthesis

\section{Up-regulated in hypertension: DNA-binding protein,} Dehydrogenase, regulatoR, membrane, oxidoreductase, Transposase, Transcriptional regulator, Mate efflux family protein, radical SAM domain protein, hydrolase family 3 , ABC transporter, Methyltransferase

Down-regulated in hypertension: Hydrolase family 2 , torsional tension of DNA, tonB-dependent Receptor, DNA binding domain, excisionase family, integrase family, TonB dependent receptor, Phage integrase family, peptidase_, Histidine kinase, acetyltransferase, Efflux transporter rnd family, mfp subunit, Ragb susd domain-containing protein, Glycosyl transferase, family 2, Membrane, Transporter, helicase, domain protein, n-acetylmuramoyl-I-alanine amidase, transposase, Hydrolase
Plasma levels of TNF, IL-6, and TNF/IFN- $\gamma$ ratio were increased in hypertension

Fecal SCFAs levels were higher and plasma SCFAs levels were lower in hypertension
Hexacosanedioic acid, Cyclophosphamide (18:1(11Z)/0:0), Lysophosphatidylethanolamine (0:0/18:2(9Z,12Z), 20:0/0:0, etc.), lysophosphatidylcholines (18:0, 15:0, etc.),

Palmitoyl-L-carnitine, $\mathrm{N}$-stearoyl glutamic acid,

Phosphocholine, Oleamide, Linoleic acid were increased in hypertension;

6-Hydroxynicotinic acid, L-Leucine, Guanidineacetic acid, Coprocholic acid, Riboflavin, 2-Oxo-4-methylthiobutanoic acid, Vitamin D3, Decenedioic acid, $\alpha$-Tocotrienol, Pantothenic Acid, Lysophosphatidic acid (0:0/18:0), tetracosahexaenoic acid, Vitamin D6, pipecolic acid, 3-Indoleacetic Acid, MG(0:0/24:6(6Z,9Z,12Z,15Z,18Z,21Z)/0:0, 0:0/22:0/0:0, etc.), Eicosanedioic acid, Vitamin D5, corticosterone, N-stearoyl tyrosine, 8(S)-HETE, Coenzyme Q4 were decreased in hypertension

Plasma butyrate levels were lower in hypertension; degradation, ABC transporters, PTS, and bacterial secretion hydrolase family 43 , integrase, Releases the supercoiling and

Up-regulated in hypertension: Membrane transport, LPS biosynthesis, steroid degradation, and enzymes involved in TMA production

Down-regulated in hypertension: metabolism of other amino acid, cofactors and vitamins (including folate biosynthesis and metabolism, riboflavin metabolism, and ubiquinone biosynthesis), and SCFA-producing enzymes
Plasma levels of I-FABP, LPS, Th17 cells were higher in hypertension
The number of hypertensionassociated species showed stronger correlation to the severity of hypertension 
TABLE 4 | Continued

\begin{tabular}{|c|c|c|c|}
\hline Study & Gut microbial functional alterations & Nutritional and immunological factors alterations & $\begin{array}{l}\text { Gut microbial } \\
\text { interactions } \\
\text { alterations }\end{array}$ \\
\hline \multicolumn{4}{|c|}{ Hypertension and borderline hypertension/Pre-hypertension } \\
\hline Huart et al. (24) & - & $\begin{array}{l}\text { Fecal SCFAs (acetate, butyrate, and propionate) levels were } \\
\text { higher in hypertension and borderline hypertension. }\end{array}$ & - \\
\hline Han et al. (20) & - & - & $\begin{array}{l}\text { Increasingly pervasive } \\
\text { virus-bacteria } \\
\text { linkages were found } \\
\text { from healthy people } \\
\text { to pre-hypertension } \\
\text { people to } \\
\text { hypertension patients }\end{array}$ \\
\hline Li et al. (18) & $\begin{array}{l}\text { Up-regulated in hypertension: LPS biosynthesis and } \\
\text { export, phospholipid transport, PTS, biosynthesis of } \\
\text { phenylalanine and phosphatidylethanolamine, and secretion } \\
\text { system } \\
\text { Down-regulated in hypertension: branched-chain amino } \\
\text { acid biosynthesis and transport, ketone body biosynthesis, } \\
\text { two-component regulatory system, and degradation of } \\
\text { methionine and purine }\end{array}$ & $\begin{array}{l}\text { Serum levels of phosphatidylserine, 3,4,5-trimethoxycinnamic } \\
\text { acid, lysophosphatidylcholine, S-carboxymethyl-L-cysteine, } \\
\text { and lysophosphatidylethanolamine were lower in hypertension } \\
\text { and pre-hypertension }\end{array}$ & - \\
\hline \multicolumn{4}{|l|}{ Preeclampsia } \\
\hline Chang et al. (30) & $\begin{array}{l}\text { Up-regulated in preeclampsia: LPS biosynthesis } \\
\text { Down-regulated in preeclampsia: GPCR pathway }\end{array}$ & $\begin{array}{l}\text { Fecal levels of butyric and valeric acids were lower in } \\
\text { preeclampsia }\end{array}$ & - \\
\hline \multicolumn{4}{|c|}{ Pulmonary arterial hypertension } \\
\hline Kim et al. (31) & $\begin{array}{l}\text { Up-regulated in PAH: Pathways for the synthesis of several } \\
\text { amino acids, including arginine, proline, lysine, homoserine, } \\
\text { methionine, ornithine, and tryptophan } \\
\text { Down-regulated in PAH: anaerobic energy metabolism, } \\
\text { gluconeogenesis, isoprene bio-synthesis, etc. }\end{array}$ & - & - \\
\hline
\end{tabular}

GPCR, G protein-coupled receptor; I-FABP, intestinal fatty acid binding protein; LPS, lipopolysaccharide; PAH, pulmonary arterial hypertension; PTS, phosphotransferase system; SBP, systolic blood pressure; SCFA, short chain fatty acid; Th17, Thelper 17; TMA, trimethylamine.

and more excretion; meanwhile, less SCFAs transportation to the bloodstream and lower level of circulating SCFAs was observed (22, 24, 29). An animal study showed reduced expression of butyrate transporter in the colon in SHR and this may explain the elevated fecal SCFAs levels and diminished SCFAs levels in circulation (42). Furthermore, blood pressure reduction was observed with the chronic intervention of acetate in mineralocorticoid excess-treated mice (37). In terms of microbe-host interactions, SCFAs can influence host cells by interacting with host $G$ protein-coupled receptors (GPCRs), including Gpr41 and Olfr78, etc. to modulate blood pressure (43). Animal studies showed that reduced intestinal absorption and delivery of SCFAs were seen in GPR41-deficient mice (44) and hypotensive response of SCFA in wild-type mice could be modulated by disruption of Olfr78 and Gpr41 expression (38). Hence, SCFAs can modulate blood pressure via GPCRs. Accordingly, GPCR pathways were down-regulated as reported in one preeclampsia study (30). These findings support the role of SCFAs in blood pressure regulation and demonstrate that poor absorption and high excretion of SCFAs may play an important role in the pathogenesis of hypertension. This will provide new insights into SCFA-targeted therapies to manage blood pressure.
Another important finding concerning inflammation is that LPS levels increased in hypertension. LPS is an abundant component within the cell wall of Gram-negative bacteria and can stimulate the release of inflammatory cytokines, inducing inflammatory response (45). A critical role for inflammation in regulation of blood pressure was seen in prospective human studies and interventional animal studies (46-49). Consistent with this hypothesis, we found that, based on the function prediction analyses, up-regulation of LPS biosynthesis was observed in hypertension group $(18,19,22)$; increase of LPS in plasma of hypertension cases was reported, indicating increased intestinal inflammatory response in hypertension (22).

Among the enrolled studies, heterogeneity of results was observed. The heterogeneity of these findings may be due to selection difference of hypertension cases and controls. As mentioned above, according to the risk of bias assessment using NOS, potential lack of representativeness of participants and selection bias were seen. Furthermore, gut microbiota composition could be influenced by various factors, of which the common ones are diet and medication factors. Thus, subjects in hypertension group and control group may have imbalanced characteristics of these factors, leading to heterogeneity of research results. 


\section{STRENGTHS AND LIMITATIONS}

To the best of our knowledge, the present study is the first systematic review to evaluate gut microbiota dysbiosis in human hypertension. We reported alterations of microbial diversity, major taxa with disparate representation, microbial function, nutritional and immunological factors, and interactions based on the enrolled studies with 9,085 participants.

We acknowledge some limitations. First, according to the risk of bias assessment, potential lack of representativeness of participants and selection bias were seen. Thus, summarized results should be interpreted with caution. Second, the diagnostic criteria for hypertension in different enrolled studies were different and this may contribute to inconsistent results of microbiota evaluation. Third, the articles which were not published in English or Chinese and did not provide English or Chinese abstracts were excluded in the present study; although only 11 studies were excluded in our study due to this reason, the generalizability of our findings might be limited. Additionally, most of the enrolled studies were conducted in China and the US and the extrapolation to other populations requires cautious interpretation.

\section{CONCLUSION}

In conclusion, gut microbiota dysbiosis was observed in hypertension, including decreased diversity, altered microbial structure, compositional change of taxa, alterations of microbial function, nutritional and immunological factors, and interactions. Poor absorption and high excretion of SCFAs

\section{REFERENCES}

1. NCD Risk Factor Collaboration (NCD-RisC). Worldwide trends in blood pressure from 1975 to 2015: a pooled analysis of 1479 population-based measurement studies with 19.1 million participants. Lancet. (2017) 389:3755. doi: 10.1016/S0140-6736(16)31919-5

2. Ehret GB, Ferreira T, Chasman DI, Jackson AU, Schmidt EM, Johnson $\mathrm{T}$, et al. The genetics of blood pressure regulation and its target organs from association studies in 342,415 individuals. Nat Genet. (2016) 48:117184. doi: $10.1038 /$ ng.3667

3. Liu C, Kraja AT, Smith JA, Brody JA, Franceschini N, Bis JC, et al. Metaanalysis identifies common and rare variants influencing blood pressure and overlapping with metabolic trait loci. Nat Genet. (2016) 48:116270. doi: 10.1038/ng.3660

4. Ezzati M, Riboli E. Behavioral and dietary risk factors for noncommunicable diseases. N Engl J Med. (2013) 369:954-64. doi: 10.1056/NEJMra1203528

5. Qi Y, Kim S, Richards EM, Raizada MK, Pepine CJ. Gut microbiota: potential for a unifying hypothesis for prevention and treatment of hypertension. Circ Res. (2017) 120:1724-6. doi: 10.1161/CIRCRESAHA.117.310734

6. Lynch SV, Pedersen O. The human intestinal microbiome in health and disease. N Engl J Med. (2016) 375:2369-79. doi: 10.1056/NEJMra1600266

7. Valdes AM, Walter J, Segal E, Spector TD. Role of the gut microbiota in nutrition and health. Bmj. (2018) 361:k2179. doi: 10.1136/bmj.k2179

8. Katsimichas T, Antonopoulos AS, Katsimichas A, Ohtani T, Sakata Y, Tousoulis D. The intestinal microbiota and cardiovascular disease. Cardiovasc Res. (2019) 115:1471-86. doi: 10.1093/cvr/cvz135

9. Streppel MT, Arends LR, van 't Veer P, Grobbee DE, Geleijnse JM. Dietary fiber and blood pressure: a meta-analysis of randomized placebo-controlled trials. Arch Intern Med. (2005) 165:150-6. doi: 10.1001/archinte.165.2.150 may play an important role in the pathogenesis of hypertension. Future studies on microbial-based therapies of hypertension are needed.

\section{DATA AVAILABILITY STATEMENT}

The raw data supporting the conclusions of this article will be made available by the authors, without undue reservation.

\section{AUTHOR CONTRIBUTIONS}

YG and BY structured and designed the study. YG and XL performed the literature search, data extraction, and wrote the first draft of the manuscript. YG and ZW evaluated the risk of bias. BY and ZW critically reviewed the manuscript. All authors approved the final version.

\section{FUNDING}

This work was supported by the National Natural Science Foundation of China (81673053), Shenzhen Sanming Project (Grant No. SZSM201812059), and Shenzhen Key Medical Discipline Construction Fund (Grant No. SZXK040).

\section{SUPPLEMENTARY MATERIAL}

The Supplementary Material for this article can be found online at: https://www.frontiersin.org/articles/10.3389/fcvm. 2021.650227/full\#supplementary-material

10. Whelton SP, Hyre AD, Pedersen B, Yi Y, Whelton PK, He J. Effect of dietary fiber intake on blood pressure: a meta-analysis of randomized, controlled clinical trials. J Hypertens. (2005) 23:475-81. doi: 10.1097/01.hjh.0000160199.51158.cf

11. Moher D, Liberati A, Tetzlaff J, Altman DG. Preferred reporting items for systematic reviews and meta-analyses: the PRISMA statement. Bmj. (2009) 339:b2535. doi: 10.1136/bmj.b2535

12. Stang A. Critical evaluation of the Newcastle-Ottawa scale for the assessment of the quality of nonrandomized studies in meta-analyses. Eur J Epidemiol. (2010) 25:603-5. doi: 10.1007/s10654-010-9491-z

13. Yeo YH, Ho HJ, Yang HI, Tseng TC, Hosaka T, Trinh HN, et al. Factors associated with rates of HBsAg seroclearance in adults with chronic HBV infection: a systematic review and meta-analysis. Gastroenterology. (2019) 156:635-46. doi: 10.1053/j.gastro.2018.10.027

14. Claesson MJ, Clooney AG, O’Toole PW. A clinician's guide to microbiome analysis. Nat Rev Gastroenterol Hepatol. (2017) 14:585-95. doi: 10.1038/nrgastro.2017.97

15. Aguilar A. Hypertension: microbiota under pressure. Nat Rev Nephrol. (2017) 13:3. doi: $10.1038 /$ nrneph.2016.173

16. Langille MG, Zaneveld J, Caporaso JG, McDonald D, Knights D, Reyes JA, et al. Predictive functional profiling of microbial communities using 16S rRNA marker gene sequences. Nat Biotechnol. (2013) 31:81421. doi: $10.1038 /$ nbt. 2676

17. Layeghifard M, Hwang DM, Guttman DS. Disentangling interactions in the microbiome: a network perspective. Trends Microbiol. (2017) 25:21728. doi: 10.1016/j.tim.2016.11.008

18. Li J, Zhao F, Wang Y, Chen J, Tao J, Tian G, et al. Gut microbiota dysbiosis contributes to the development of hypertension. Microbiome. (2017) 5:14. doi: 10.1186/s40168-016-0222-x 
19. Yan Q, Gu Y, Li X, Yang W, Jia L, Chen C, et al. Alterations of the gut microbiome in hypertension. Front Cell Infect Microbiol. (2017) 7:381. doi: 10.3389/fcimb.2017.00381

20. Han MZ, Yang PS, Zhong CF, Ning K. The human gut virome in hypertension. Front Microbiol. (2018) 9:10. doi: 10.3389/fmicb.2018.03150

21. Jin L, Cui X, Cai J. Study of gut microbiota in over-weighted and obese hypertensive patients. Infect Dis Informat. (2018) 31:320-325. doi: 10.3969/j.issn.1007-8134.2018.04.005

22. Kim S, Goel R, Kumar A, Qi Y, Lobaton G, Hosaka K, et al. Imbalance of gut microbiome and intestinal epithelial barrier dysfunction in patients with high blood pressure. Clin Sci (Lond). (2018) 132:701-18. doi: 10.1042/CS20180087

23. Dan X, Mushi Z, Baili W, Han L, Enqi W, Huanhu Z, et al. Differential analysis of hypertension-associated intestinal microbiota. Int J Med Sci. (2019) 16:872-81. doi: 10.7150/ijms.29322

24. Huart J, Leenders J, Taminiau B, Descy J, Saint-Remy A, Daube G, et al. Gut microbiota and fecal levels of short-chain fatty acids differ upon 24-hour blood pressure levels in men. Hypertension. (2019) 74:100513. doi: 10.1161/HYPERTENSIONAHA.118.12588

25. Li HJ, Liu BD, Song J, An Z, Zeng X, Li J, et al. Characteristics of gut microbiota in patients with hypertension and/or hyperlipidemia: a cross-sectional study on rural residents in Xinxiang County, Henan Province. Microorganisms. (2019) 7:13. doi: 10.3390/microorganisms7100399

26. Mushtaq N, Hussain S, Zhang S, Yuan L, Li H, Ullah S, et al. Molecular characterization of alterations in the intestinal microbiota of patients with grade 3 hypertension. Int J Mol Med. (2019) 44:51322. doi: 10.3892/ijmm.2019.4235

27. Sun S, Lulla A, Sioda M, Winglee K, Wu MC, Jacobs R, Jr., et al. Gut microbiota composition and blood pressure. Hypertension. (2019) 73:9981006. doi: 10.1161/HYPERTENSIONAHA.118.12109

28. Zuo K, Li J, Xu QH, Hu CW, Gao YF, Chen ML, et al. Dysbiotic gut microbes may contribute to hypertension by limiting vitamin D production. Clin Cardiol. (2019) 42:710-9. doi: 10.1002/clc.23195

29. Calderon-Perez L, Gosalbes MJ, Yuste S, Valls RM, Pedret A, Llaurado E, et al. Gut metagenomic and short chain fatty acids signature in hypertension: a cross-sectional study. Sci Rep. (2020) 10:16. doi: 10.1038/s41598-020-63475-w

30. Chang Y, Chen Y, Zhou Q, Wang C, Chen L, Di W, et al. Short-chain fatty acids accompanying changes in the gut microbiome contribute to the development of hypertension in patients with preeclampsia. Clin Sci (Lond). (2020) 134:289-302. doi: 10.1042/CS20191253

31. Kim S, Rigatto K, Gazzana MB, Knorst MM, Richards EM, Pepine CJ, et al. Altered gut microbiome profile in patients with pulmonary arterial hypertension. Hypertension. (2020) 75:1063-71. doi: 10.1161/HYPERTENSIONAHA.119.14294

32. Palmu J, Salosensaari A, Havulinna AS, Cheng S, Inouye $M$, Jain $M$, et al. Association between the gut microbiota and blood pressure in a population cohort of 6953 individuals. J Am Heart Assoc. (2020) 9:e016641. doi: 10.1161/JAHA.120.016641

33. Silveira-Nunes G, Durso DF, Oliveira LRA, Jr., Cunha EHM, Maioli TU. Vieira AT, et al. Hypertension is associated with intestinal microbiota dysbiosis and inflammation in a Brazilian population. Front Pharmacol. (2020) 11:258. doi: 10.3389/fphar.2020.00258

34. Takagi T, Naito Y, Kashiwagi S, Uchiyama K, Mizushima K, Kamada K, et al. Changes in the gut microbiota are associated with hypertension, hyperlipidemia, and type 2 diabetes mellitus in japanese subjects. Nutrients. (2020) 12:13. doi: 10.3390/nu12102996

35. Yang T, Santisteban MM, Rodriguez V, Li E, Ahmari N, Carvajal JM, et al. Gut dysbiosis is linked to hypertension. Hypertension. (2015) 65:133140. doi: 10.1161/HYPERTENSIONAHA.115.05315

36. Durgan DJ, Ganesh BP, Cope JL, Ajami NJ, Phillips SC, Petrosino JF, et al. Role of the gut microbiome in obstructive sleep apnea-induced hypertension. Hypertension. (2016) 67:46974. doi: 10.1161/HYPERTENSIONAHA.115.06672

37. Marques FZ, Nelson E, Chu, P-Y, Horlock D, Fiedler A, et al. High-fiber diet and acetate supplementation change the gut microbiota and prevent the development of hypertension and heart failure in hypertensive mice. Circulation. (2017) 135:96477. doi: 10.1161/CIRCULATIONAHA.116.024545

38. Pluznick JL, Protzko RJ, Gevorgyan H, Peterlin Z, Sipos A, Han J, et al. Olfactory receptor responding to gut microbiota-derived signals plays a role in renin secretion and blood pressure regulation. Proc Natl Acad Sci USA. (2013) 110:4410-5. doi: 10.1073/pnas.1215927110

39. Bartolomaeus H, Balogh A, Yakoub M, Homann S, Markó L, Höges S, et al. Short-chain fatty acid propionate protects from hypertensive cardiovascular damage. Circulation. (2019) 139:1407-21. doi: 10.1161/CIRCULATIONAHA.118.036652

40. Vogt JA, Wolever TM. Fecal acetate is inversely related to acetate absorption from the human rectum and distal colon. J Nutr. (2003) 133:31458. doi: $10.1093 /$ jn/133.10.3145

41. Clarke G, Stilling RM, Kennedy PJ, Stanton C, Cryan JF, Dinan TG. Minireview: gut microbiota: the neglected endocrine organ. Mol Endocrinol. (2014) 28:1221-38. doi: 10.1210/me.2014-1108

42. Yang T, Magee KL, Colon-Perez LM, Larkin R, Liao YS, Balazic E, et al. Impaired butyrate absorption in the proximal colon, low serum butyrate and diminished central effects of butyrate on blood pressure in spontaneously hypertensive rats. Acta Physiol. (2019) 226:e13256. doi: 10.1111/apha. 13256

43. Pluznick JL. Microbial short-chain fatty acids and blood pressure regulation. Curr Hypertens Rep. (2017) 19:25. doi: 10.1007/s11906-017-0722-5

44. Samuel BS, Shaito A, Motoike T, Rey FE, Backhed F, Manchester JK, et al. Effects of the gut microbiota on host adiposity are modulated by the shortchain fatty-acid binding G protein-coupled receptor, Gpr41. Proc Natl Acad Sci USA. (2008) 105:16767-72. doi: 10.1073/pnas.0808567105

45. Ngkelo A, Meja K, Yeadon M, Adcock I, Kirkham PA. LPS induced inflammatory responses in human peripheral blood mononuclear cells is mediated through NOX4 and Gi $\alpha$ dependent PI-3kinase signalling. J Inflamm. (2012) 9:1. doi: 10.1186/1476-9255-9-1

46. Sesso HD, Buring JE, Rifai N, Blake GJ, Gaziano JM, Ridker PM. C-reactive protein and the risk of developing hypertension. JAMA. (2003) 290:294551. doi: 10.1001/jama.290.22.2945

47. Wei YL, Li XH, Zhou JZ. Prenatal exposure to lipopolysaccharide results in increases in blood pressure and body weight in rats. Acta Pharmacol Sin. (2007) 28:651-6. doi: 10.1111/j.1745-7254.2007.00593.x

48. Carbone F, Elia E, Casula M, Bonaventura A, Liberale L, Bertolotto M, et al. Baseline hs-CRP predicts hypertension remission in metabolic syndrome. Eur J Clin Invest. (2019) 49:e13128. doi: 10.1111/eci.13128

49. Ferguson JF, Aden LA, Barbaro NR, Van Beusecum JP, Xiao L, Simons AJ, et al. (2019) High dietary salt-induced dendritic cell activation underlies microbial dysbiosis-associated hypertension. JCI Insight 5:126241. doi: 10.1172/jci.insight.126241

Conflict of Interest: The authors declare that the research was conducted in the absence of any commercial or financial relationships that could be construed as a potential conflict of interest.

Copyright (c) $2021 \mathrm{Guo}, \mathrm{Li}$, Wang and Yu. This is an open-access article distributed under the terms of the Creative Commons Attribution License (CC BY). The use, distribution or reproduction in other forums is permitted, provided the original author(s) and the copyright owner(s) are credited and that the original publication in this journal is cited, in accordance with accepted academic practice. No use, distribution or reproduction is permitted which does not comply with these terms. 